\title{
ORIGINAL ARTICLE Prognostic impact of bone marrow fibrosis in polycythemia vera: validation of the IWG-MRT study and additional observations
}

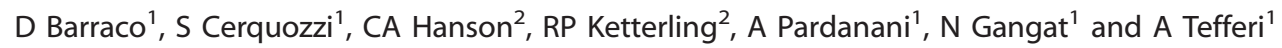

In 2012, the International Working Group for Myeloproliferative Neoplasms (MPN) Research and Treatment (IWG-MRT) reported an associations between mild bone marrow (BM) fibrosis ( $\geqslant$ grade 1 ) in polycythemia vera (PV) and a lower incidence of thrombosis during the clinical course and a higher risk of fibrotic progression. The objective in the current study of 262 patients with PV was to validate these observations and also identify other risk factors for myelofibrosis-free survival (MFFS). About 127 (48\%) patients displayed $\geqslant$ grade 1 reticulin fibrosis at the time of diagnosis; presenting clinical and laboratory features were not significantly different between patients with or without BM fibrosis. In univariate analysis, BM fibrosis had no significant impact on overall, leukemia-free or thrombosis-free survival, whereas a significant association was noted for MFFS $(P=0.009$, hazard ratio 2.9 ; $95 \%$ confidence interval 1.32-6.78); other risk factors for MFFS included leukocytosis $\geqslant 15 \times 10^{9} /$, presence of palpable splenomegaly and abnormal karyotype. During multivariable analysis, leukocytosis $\geqslant 15 \times 10^{9} / \mathrm{l}$, palpable splenomegaly and $\geqslant$ grade $1 \mathrm{BM}$ reticulin fibrosis remained significant. The current study validates the previously observed association between $\geqslant$ grade 1 BM reticulin fibrosis in PV and subsequent fibrotic progression, and identifies leukocytosis and palpable splenomegaly as additional risk factors for fibrotic progression; additional studies are required to clarify the impact of BM fibrosis on thrombosis and that of abnormal karyotype on MFFS.

Blood Cancer Journal (2017) 7, e538; doi:10.1038/bcj.2017.17; published online 10 March 2017

\section{INTRODUCTION}

Polycythemia Vera (PV) is a $B C R-A B L 1$ negative myeloproliferative neoplasm (MPN) characterized by clonal erythrocytosis and a JAK2 mutation, either JAK2V617F or an exon 12 mutation, in $96 \%$ and $3 \%$ of cases, respectively. ${ }^{1}$ Life expectancy in PV has been shown to be worse than that of the age- and sex-matched US population, with a median survival of 14 years and 24 years in patients younger than age 60 years. $^{2}$ Disease-related complications affecting survival in PV are thrombotic complications and disease progression into acute myeloid leukemia or myelofibrosis (MF). ${ }^{3}$ Numerous prognostic factors have been identified as being involved in clinical phenotype, disease progression and survival of PV patients. Tefferi et al. ${ }^{2}$ have identified leukocytosis, advanced age and venous thrombosis history as independent risk factors for overall survival (OS); myelofibrosis-free survival (MFFS) was reportedly affected by leukocytosis, older age, JAK2V617F allele burden, palpable splenomegaly, thrombocytosis and mild bone marrow (BM) fibrosis, whereas leukemia-free survival (LFS) was affected by advanced age, leukocytosis, abnormal karyotype, palpable splenomegaly and BM fibrosis. ${ }^{2-7}$

As highlighted by the recently updated 2016 World Health Organization (WHO) classification of myeloid neoplasms and acute leukemia, ${ }^{8}$ specific histopathological BM features have a central role in the diagnosis of myeloproliferative neoplasms; furthermore, the degree of BM fibrosis might identify a more aggressive disease. ${ }^{9,10}$ Increased BM reticulin fibrosis ( $\geqslant$ grade 1 ) in PV has been reported in $20 \%^{11,12}-51 \%^{7}$ of patients at time of diagnosis. In a previous report by the International Working Group for Myeloproliferative Neoplasms (MPN) Research and Treatment (IWG-MRT), mostly mild BM reticulin fibrosis ( $\geqslant$ grade 1 of a threegraded score system) at diagnosis was associated with a lower risk of thrombosis during the clinical course and a higher risk of fibrotic progression while it did not affect OS or LFS. ${ }^{13}$ The objectives for the current single-center study were to validate the observations from the IWG-MRT and also identify other risk factors for MFFS.

\section{MATERIALS AND METHODS}

This study was approved by the institutional review board of Mayo Clinic (Rochester, MN). Study patients were selected from our institutional database of myeloproliferative neoplasm and fulfilled the 2016 WHO criteria for the diagnosis of PV. ${ }^{8}$ Clinical data collected were from the time of diagnosis. Cytogenetic analysis and reporting was done according to the International System for Human Cytogenetic Nomenclature. ${ }^{14}$ The degree of BM reticulin was based on 'real life' BM reports from Mayo Clinic hematopathologists and in accordance with the European consensus scoring system. ${ }^{15}$ Screening for the two most frequent and prognostically important mutations in $\mathrm{PV}^{16}$ other than JAK2 (that is, TET2 and ASXL1) were performed according to conventional methods. ${ }^{17}$ Differences in the distribution of continuous variables between categories were analyzed by either Mann-Whitney U-(for comparison of two groups) or KruskalWallis test (comparison of three or more groups). Patient groups with nominal variables were compared by $\times 2$-test. OS analysis was considered from the date of diagnosis to date of death (uncensored) or last contact (censored). MFFS, LFS and thrombosis-free survivals were determined from

\footnotetext{
'Division of Hematology, Department of Medicine, Mayo Clinic, Rochester, MN, USA and 2Department of Laboratory and Pathology, Mayo Clinic, Rochester, MN, USA. Correspondence: Dr A Tefferi, Division of Hematology, Department of Medicine, Mayo Clinic, 200 First Street SW, Rochester, MN 55905, USA.

E-mail: tefferi.ayalew@mayo.edu

Received 16 January 2017; accepted 25 January 2017
} 
the time of diagnosis to the time the events occurrence after diagnosis (uncensored) or last contact/date of death (censored). All survival curves were prepared by the Kaplan-Meier methods and compared by the longrank test. Cox proportional hazard regression model was applied to carry out multivariable analysis. $P$-values $<0.05$ were considered significant. The Stat View (SAS Institute, Cary, NC, USA) statistical package was used for all calculations.

\section{RESULTS}

Analysis was conducted on 262 patients who met 2016 WHO criteria of PV, and their clinical and laboratory characteristics are listed in Table 1. The median age was 62 years and 50\% were males. Median values of hemoglobin, leukocytes and platelets were $18 \mathrm{~g} / \mathrm{dl}, 11.7 \times 10^{9} / \mathrm{I}$ and $454 \times 10^{9} / \mathrm{l}$, respectively. Among informative cases, palpable splenomegaly was present in $27 \%$, pruritus in $33 \%$ and erythromelalgia in $6 \%$. Thrombosis history at diagnosis was documented in $28 \%$ of the patients and
$23 \%$ experienced thrombotic events after diagnosis. Mutational frequencies included, JAK2 ( $n$ evaluable $=258,97 \%)$ TET2 ( $n$ evaluable $=80) \quad 20 \%$ and ASXL1 ( $n$ evaluable $=80$ ) 10\%, respectively. Information on cytogenetic was available in 142 patients and karyotype was abnormal in 19\%.

The cytogenetic abnormalities found at diagnosis were: isolated trisomy 9 (8 cases, 29\%), loss of $Y$ chromosome (5 cases, 18\%), isolated trisomy 8 (5 cases, 19\%), isolated deletion 20 q (3 cases, $11 \%)$, isolated deletion $13 q$ ( 2 cases, $7 \%$ ), inversion of chromosome 1 (1 case, 4\%), unbalanced translocation between chromosomes 9 and 18 ( 1 case, 4\%), inversion of chromosome 2 (1 case, $4 \%)$ and concomitant presence of trisomy chromosome 9 and deletion $13 \mathrm{q}$ ( 1 case, $4 \%$ ). BM reticulin fibrosis was reported to be absent in 135 patients (MF-0,52\%), grade 1 (MF-1) in 101 patients (39\%), grade 2 (MF-2) in 22 patients (8\%) and grade 3 (MF-3) in 4 (2\%) patients. After a median follow up of 85 months, 107 (41\%) deaths, $30(11 \%)$ fibrotic progression and 5 (2\%) leukemic transformations were documented.

Table 1. Presenting clinical and laboratory features of 262 patients with polycythemia vera stratified by the presence of grade 1 or greater bone marrow reticulin fibrosis

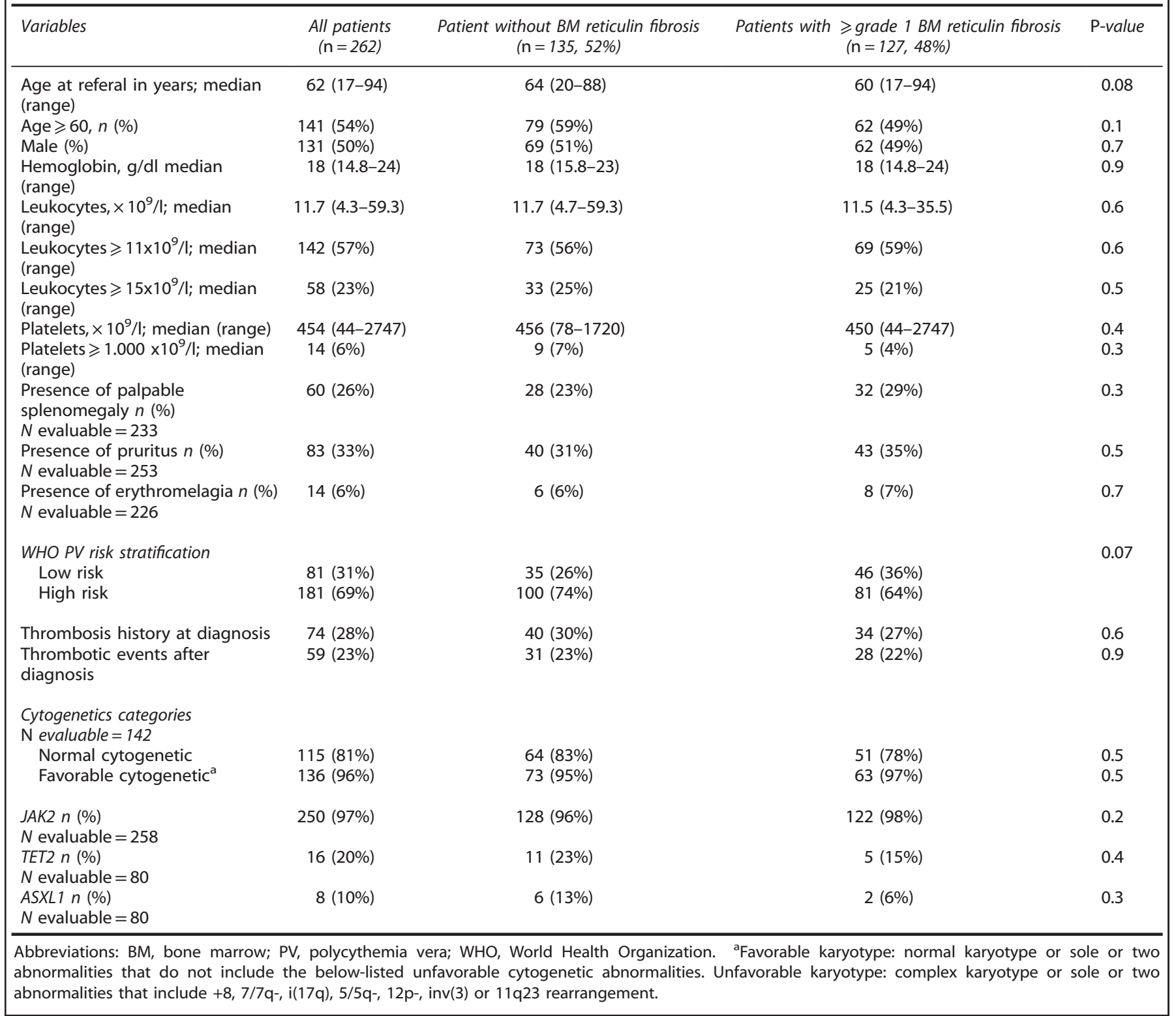


a Overall survival for 262 patients with Polycythemia Vera stratified by the presence of grade 1 or greater bone marrow reticulin fibrosis

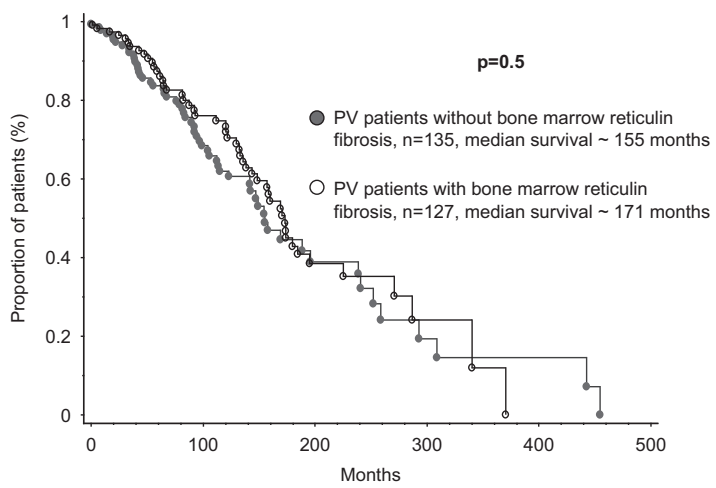

C Thrombosis-free survival for 262 patients with Polycythemia Vera stratified by the presence of grade 1 or greater bone marrow reticulin fibrosis.



b

Leukemia-free survival for 262 patients with Polycythemia Vera stratified by the presence of grade 1 or greater bone marrow reticulin fibrosis.

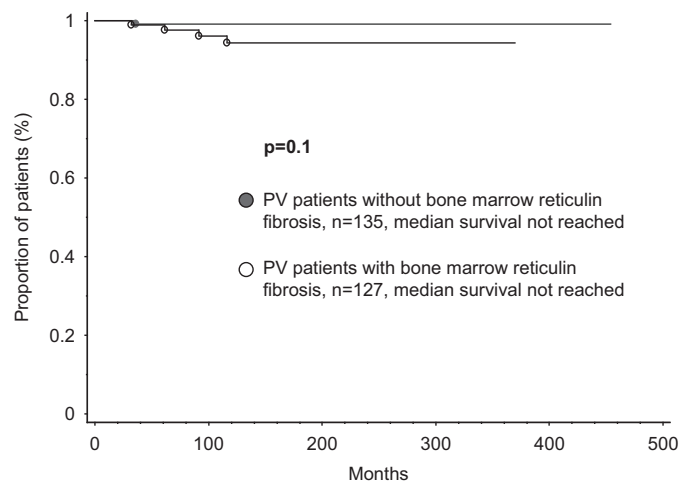

d Myelofibrosis-free survival for 262 patients with Polycythemia Vera stratified by the presence of grade 1 or greater bone marrow reticulin fibrosis.

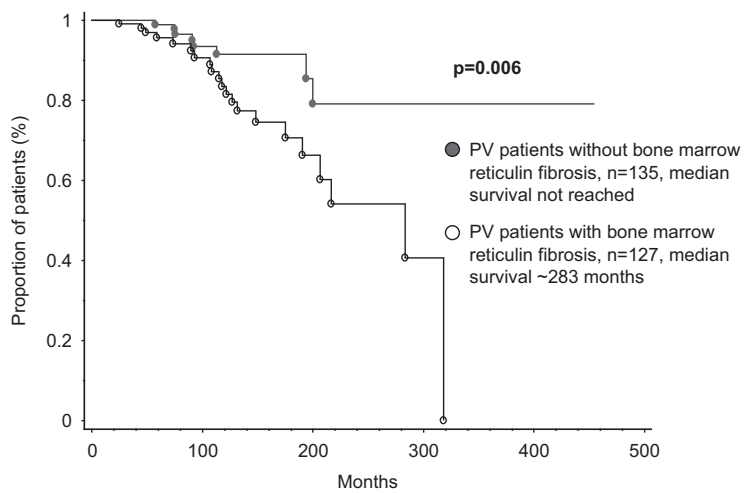

Figure 1. Kaplan-Meier curves representing OS (a), LFS (b), thrombosis-free survival (TFS) (c) and MFFS (d) in 262 patients with polycythemia vera stratified by the presence of grade 1 or greater bone marrow reticulin fibrosis (Table 2).

The study population was subsequently stratified according to the presence ( $\geqslant$ grade $1 \mathrm{BM}$ fibrosis) or absence of $\mathrm{BM}$ reticulin fibrosis. A number of clinical and laboratory parameters were evaluated for possible association with the presence of $\geqslant$ grade 1 BM reticulin fibrosis and none, including age $(P=0.1)$, sex $(P=0.7)$, hemoglobin level $(P=0.9)$, leukocyte count $(P=0.6)$, leukocytosis $\geqslant 11 \times 10^{9} / \mathrm{I} \quad(P=0.6)$, leukocytosis $\geqslant 15 \times 10^{9} / \mathrm{I} \quad(P=0.5)$, platelet count $(P=0.4)$, presence of palpable splenomegaly $(P=0.3)$, pruritus $(P=0.5)$, erythromelalgia $(P=0.7)$ or mutations (JAK2, $P=0.2 ;$ TET2, $P=0.4 ; \quad A S X L 1, P=0.3$ ) displayed a significant association (Table 1).

In univariate analysis, OS was adversely affected by age (as a continuous variable and as $>60$ years, $P<0.0001$ and $P<0.0001$, hazard ratio (HR) 5.1; 95\% confidence interval (CI) 3.25-8.07, respectively), leukocytosis $\geqslant 11 \times 10^{9} / \mathrm{I}(P=0.03, \mathrm{HR} 1.6 ; 95 \% \mathrm{Cl}$ $1.05-2.34)$ and $\geqslant 15 \times 10^{9} / \mathrm{I}(P=0.0001$, HR 2.2; $95 \% \mathrm{Cl} 1.48-3.41)$ thrombosis history $(P=0.005, \mathrm{HR} 1.8 ; 95 \% \mathrm{Cl} 1.19-2.71)$ and the presence of $A S X L 1$ mutations ( $P=0.006, \mathrm{HR} 3.6 ; 95 \% \mathrm{Cl} 1.43-8.97$ ) but not by the presence of grade $\geqslant 1 \mathrm{BM}$ reticulin fibrosis (Figure 1a; $P=0.5$ ); in multivariate analysis, older age ( $>60$ years), leukocytosis $\left(\geqslant 15 \times 10^{9} / \mathrm{l}\right)$ and the presence of $A S X L 1$ mutation retained significance for $\mathrm{OS}(P<0.0001, P=0.001$ and $P=0.0006$, respectively). LFS was negatively affected by the presence of palpable splenomegaly $(P=0.03, \mathrm{HR} 11.4 ; 95 \% \mathrm{Cl} 1.27-101.90)$ but not by $B M$ reticulin fibrosis (Figure $1 \mathrm{~b} ; P=0.1$ ); the latter did not affect thrombosis-free survival either (Figure 1c; $P=0.9$ ).

Patients with grade 1 or greater $\mathrm{BM}$ reticulin fibrosis were more prone to fibrotic progression (Figure 1d; $P=0.006, \mathrm{HR} 2.9 ; 95 \% \mathrm{Cl}$ 1.32-6.78). Other risk factors found to be prognostically significant for MFFS in univariate analysis were leukocytosis $\geqslant 15 \times 10^{9} /$ I
$(P=0.02, \quad H R 2.8 ; 95 \% \mathrm{Cl} 1.17-6.48)$, presence of palpable splenomegaly $(P=0.02, \mathrm{HR} 2.6 ; 95 \% \mathrm{Cl} 1.14-6.08)$ and abnormal karyotype $(P=0.008, \mathrm{HR} 6.3 ; 95 \% \mathrm{Cl} 1.62-24.84)$; on multivariable analysis, leukocytosis $\geqslant 15 \times 10^{9} / \mathrm{l}(P=0.04, \mathrm{HR} 2.8$; $95 \% \mathrm{Cl} 1.02-$ 7.62), presence of splenomegaly $(P=0.04$, HR 2.4; $95 \% \mathrm{Cl} 1.02-5.8)$ and presence of $\mathrm{BM}$ reticulin fibrosis $(P=0.02, \mathrm{HR} 3.3 ; 95 \% \mathrm{Cl}$ 1.24-8.60) remained significant (Table 2 ). Presence of abnormal karyotype was significant in univariate analysis for MFFS $(P=0.008$, HR 6.3; $95 \% \mathrm{Cl} 1.62-24.84)$ and was of borderline significance during multivariable analysis $(P=0.06)$; a similar trend of significance was noted between abnormal karyotype and LFS $(P=0.05$; data not shown).

\section{DISCUSSION}

The IWG-MRT previously evaluated the prognostic significance of grade $\geqslant 1$ BM fibrosis in 526 patients with PV and reported on the impact of BM fibrosis on thrombosis-free survival (favorable) and MFFS (unfavorable), without affecting OS or LFS. ${ }^{13}$ In the current study, we sought to validate these previous observations and identify additional risk factors for MFFS. The two studies (the aforementioned IWG-MRT and the current study) were concordant in their observations regarding the lack of associations with OS and LFS, and the unfavorable impact of BM fibrosis on MFFS; the discrepancy on the association with thrombosis-free survival requires additional studies for clarification. Regardless, it is not appropriate to directly compare the two studies as the subjective criteria for BM fibrosis might have been different; for example, the incidence of grade $\geqslant 1 \mathrm{BM}$ fibrosis in the current study was much higher than the one reported by the IWG-MRT study ( $48 \%$ vs $14 \%$, 
Table 2. Univariate and multivariate analysis of prognostic factors for overall, myelofibrosis and leukemia-free survivals in patients with polycythemia vera $(n=262)$

\begin{tabular}{|c|c|c|c|c|c|c|}
\hline \multirow[t]{2}{*}{ Variables } & \multicolumn{2}{|c|}{ Overall survival } & \multicolumn{2}{|c|}{ Myelofibrosis-free survival } & \multicolumn{2}{|c|}{ Leukemia-free survival } \\
\hline & Univariate analysis & Multivariate analysis & $\begin{array}{l}\text { Univariate } \\
\text { analysis }\end{array}$ & $\begin{array}{c}\text { Multivariate } \\
\text { analysis }\end{array}$ & Univariate analysis & $\begin{array}{c}\text { Multivariate } \\
\text { analysis }\end{array}$ \\
\hline $\begin{array}{l}\text { BM reticulin } \\
\text { fibrosis } \geqslant \text { grade } 1\end{array}$ & $P=0.5$ & & $\begin{array}{c}P=0.009 \\
\text { HR } 2.9 ; 95 \% \text { Cl } \\
1.32-6.78\end{array}$ & $\begin{array}{c}P=0.02 \\
\text { HR } 3.3 ; 95 \% \mathrm{Cl} \\
1.24-8.60\end{array}$ & $P=0.2$ & NA \\
\hline & $\begin{array}{c}\text { HR } 5.1 ; 95 \% \mathrm{Cl} \\
3.25-8.07\end{array}$ & $\begin{array}{c}\text { HR } 6.1 ; 95 \% \mathrm{Cl} \\
2.66-13.96\end{array}$ & & & & \\
\hline Hemoglobin, g/dl & $P=0.6$ & & $P=0.3$ & & $P=0.6$ & NA \\
\hline Platelets, $\times 10^{9} / \mathrm{I}$ & $P=0.2$ & & $P=0.8$ & & $P=0.08$ & NA \\
\hline WBC $\times 10^{9} / \mathrm{I}$ & $P=0.0002$ & & $P=0.1$ & & $P=0.9$ & NA \\
\hline$W B C \geqslant 11 \times 10^{9} / I$ & $P=0.03$ & & $P=0.4$ & & $P=0.7$ & NA \\
\hline $\begin{array}{l}\text { Palpable splenomegaly at } \\
\text { diagnosis }\end{array}$ & $P=0.1$ & & $\begin{array}{c}P=0.02 \\
\text { HR } 2.6 ; 95 \% \mathrm{Cl} \\
1.14-6.08\end{array}$ & $\begin{array}{c}P=0.04 \\
\text { HR } 2.4 ; 95 \% \mathrm{Cl} \\
1.02-5.8\end{array}$ & $\begin{array}{c}P=0.03 \\
\text { HR } 11.4 ; 95 \% \mathrm{Cl} \\
1.27-101.90\end{array}$ & NA \\
\hline Presence of pruritus & $P=0.6$ & & $P=0.09$ & & $P=0.3$ & NA \\
\hline $\begin{array}{l}\text { Presence of } \\
\text { erythromelagia }\end{array}$ & $P=0.8$ & & $P=0.8$ & & $P=0.2$ & NA \\
\hline Thrombosis history & $\begin{array}{c}P=0.005 \\
\text { HR } 1.8 ; 95 \% \mathrm{Cl} \\
1.19-2.71\end{array}$ & $P=0.2$ & $P=0.5$ & & NA & \\
\hline $\begin{array}{l}\text { Thrombotic events after } \\
\text { diagnosis }\end{array}$ & $P=0.9$ & & $P=0.7$ & & NA & NA \\
\hline$J A K 2$ & $P=0.47$ & & $P=0.6$ & & NA & \\
\hline TET2 & $P=0.2$ & & $P=0.8$ & & NA & \\
\hline
\end{tabular}

respectively) and we reported a higher proportion of cases with higher degree of fibrosis (MF-2 and MF-3, 26 vs 2 cases, respectively). In this regard, it is important to note that our study populations with or without BM fibrosis were similar in their presenting clinical and laboratory features (Table 1).

In both the current study and that of the IWG-MRT, the presence of mild BM fibrosis did not affect OS or LFS; in the current study, risk factors for OS or LFS included advanced age ( $\geqslant 60$ years), leukocytosis $\left(\geqslant 15 \times 10^{9} / \mathrm{l}\right)$, ASXL1 mutations and palpable splenomegaly, and these observations were consistent with previous reports. $2,7,13,18$ The current study also shows the limited prognostic relevance of $A S X L 1$ or TET2 mutations for MFFS, whereas a possible impact from abnormal karyotype was suggested despite the lower number of informative cases; the latter has previously been shown to affect both OS and LFS in PV. 2,18,19

The current study highlights the overall prognostic value of including BM examination during the diagnostic evaluation of PV, by demonstrating associations between fibrotic progression and the presence of mild reticulin fibrosis or abnormal karyotype at the time of diagnosis. Additional validation studies are required to confirm the association between fibrotic progression and abnormal karyotype, and resolve the discrepancy between the current study and that of the IWG-MRT, in terms of the association between BM fibrosis and risk of thrombosis.

\section{CONFLICT OF INTEREST}

The authors declare no conflict of interest.

\section{REFERENCES}

1 Tefferi A, Barbui T. Polycythemia vera and essential thrombocythemia: 2017 update on diagnosis, risk-stratification, and management. Am J Hematol 2017; 92: 94-108.

2 Tefferi A, Rumi E, Finazzi G, Gisslinger $H$, Vannucchi AM, Rodeghiero $F$ et al. Survival and prognosis among 1545 patients with contemporary polycythemia vera: an international study. Leukemia 2013; 27: 1874-1881.

3 Cerquozzi S, Tefferi A. Blast transformation and fibrotic progression in polycythemia vera and essential thrombocythemia: a literature review of incidence and risk factors. Blood Cancer J 2015; 5: e366.

4 Passamonti F, Rumi E, Pietra D, Elena C, Boveri E, Arcaini L et al. A prospective study of 338 patients with polycythemia vera: the impact of JAK2 (V617F) allele burden and leukocytosis on fibrotic or leukemic disease transformation and vascular complications. Leukemia 2010; 24: 1574-1579.

5 Cervantes F, Passamonti F, Barosi G. Life expectancy and prognostic factors in the classic BCR/ABL-negative myeloproliferative disorders. Leukemia 2008; 22: 905-914.

6 Tiribelli M, Barraco D, De Marchi F, Marin L, Medeot M, Damiani D et al. Clinical factors predictive of myelofibrotic evolution in patients with polycythemia vera. Ann Hematol 2015; 94: 873-874.

7 Abdulkarim K, Ridell B, Johansson P, Kutti J, Safai-Kutti S, Andreasson B. The impact of peripheral blood values and bone marrow findings on prognosis for 
patients with essential thrombocythemia and polycythemia vera. Eur J Haematol 2011; 86: 148-155.

8 Arber DA, Orazi A, Hasserjian R, Thiele J, Borowitz MJ, Le Beau MM et al. The 2016 revision to the World Health Organization classification of myeloid neoplasms and acute leukemia. Blood 2016; 127: 2391-2405.

9 Guglielmelli P, Rotunno G, Pacilli A, Rumi E, Rosti V, Delaini F et al. Prognostic impact of bone marrow fibrosis in primary myelofibrosis. A study of the AGIMM group on 490 patients. Am J Hematol 2016; 91: 918-922.

10 Kvasnicka HM, Thiele J. The impact of clinicopathological studies on staging and survival in essential thrombocythemia, chronic idiopathic myelofibrosis, and polycythemia rubra vera. Semin Thromb Hemost 2006; 32(4 Pt 2): 362-371.

11 Kreft A, Buche G, Ghalibafian M, Buhr T, Fischer T, Kirkpatrick CJ. The incidence of myelofibrosis in essential thrombocythaemia, polycythaemia vera and chronic idiopathic myelofibrosis: a retrospective evaluation of sequential bone marrow biopsies. Acta Haematol 2005; 113: 137-143.

12 Thiele J, Kvasnicka HM, Fischer R. Histochemistry and morphometry on bone marrow biopsies in chronic myeloproliferative disorders - aids to diagnosis and classification. Ann Hematol 1999; 78: 495-506.

13 Barbui T, Thiele J, Passamonti F, Rumi E, Boveri E, Randi ML et al. Initial bone marrow reticulin fibrosis in polycythemia vera exerts an impact on clinical outcome. Blood 2012; 119: 2239-2241.

14 Simons A, Shaffer LG, Hastings RJ. Cytogenetic nomenclature: changes in the ISCN 2013 compared to the 2009 edition. Cytogenet Genome Res 2013; 141: $1-6$.
15 Thiele J, Kvasnicka HM, Facchetti F, Franco V, van der Walt J, Orazi A. European consensus on grading bone marrow fibrosis and assessment of cellularity. Haematologica 2005; 90: 1128-1132.

16 Tefferi A. Myeloproliferative neoplasms: a decade of discoveries and treatment advances. Am J Hematol 2016; 91: 50-58.

17 Patnaik MM, Itzykson R, Lasho TL, Kosmider O, Finke CM, Hanson CA et al. ASXL1 and SETBP1 mutations and their prognostic contribution in chronic myelomonocytic leukemia: a two-center study of 466 patients. Leukemia 2014; 28: 2206-2212.

18 Sever M, Quintas-Cardama A, Pierce S, Zhou L, Kantarjian H, Verstovsek S. Significance of cytogenetic abnormalities in patients with polycythemia vera. Leuk Lymphoma 2013; 54: 2667-2670.

19 Gangat N, Strand J, Lasho TL, Finke CM, Knudson RA, Pardanani A et al. Cytogenetic studies at diagnosis in polycythemia vera: clinical and JAK2V617F allele burden correlates. Eur J Haematol 2008; 80: 197-200.

(c) (i) This work is licensed under a Creative Commons Attribution 4.0 International License. The images or other third party material in this article are included in the article's Creative Commons license, unless indicated otherwise in the credit line; if the material is not included under the Creative Commons license, users will need to obtain permission from the license holder to reproduce the material. To view a copy of this license, visit http://creativecommons.org/licenses/ by/4.0/

(c) The Author(s) 2017 